\title{
GruPOS DE SAÚDE MENTAL NA ATENÇÃo PRIMÁRIA À SAÚDE
}

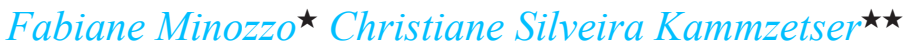

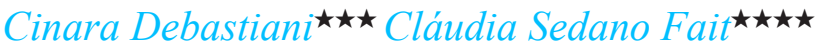 \\ Simone Mainieri Paulon
}

\begin{abstract}
Resumo
Trata-se de uma pesquisa qualitativa, do tipo pesquisa-intervenção, realizada em duas equipes de Atenção Primária à Saúde que objetivou analisar as práticas de cuidado desenvolvidas nos grupos de saúde mental e a sua correspondência com os processos de desinstitucionalização da loucura, inscritos na reforma psiquiátrica brasileira. Utilizou como métodos de investigação: intervenções nos grupos de saúde mental, entrevistas semiestruturadas, oficinas com os profissionais das equipes e diário de campo. Os resultados apontaram para uma compreensão do grupo de saúde mental como dispositivo desinstitucionalizante quando este se constitui em um espaço de cuidado psicossocial, utiliza-se da rede de saúde, dos recursos do território, da ampliação dos laços sociais e permite aos participantes perceberem-se sujeitos protagonistas de suas vidas. Também indicaram a coexistência dos modos de atenção asilar e psicossocial nas práticas dos profissionais. Como estratégias para o fortalecimento da atenção psicossocial foram indicadas a educação permanente e as trocas multiprofissionais.
\end{abstract}

Palavras-chave: Atenção Primária à Saúde; Saúde Mental; Grupos; Desinstitucionalização; Pesquisa-intervenção.

^ Psicóloga. Mestra em Psicologia Clínica e Cultura pela Universidade de Brasília. Especialista em atenção primária à saúde pela Escola de Saúde Pública/Centro de Saúde Escola Murialdo e especialista em saúde mental pela Universidade de Brasília.

E-mail: fabiminozzo@yahoo.com.br

$\star \star$ Psicóloga. Graduada em Psicologia pela Universidade Federal do Rio Grande do Sul, realizou Especialização pelo "Programa de Residência Integrada em Saúde, Aperfeiçoamento Especializado em Saúde Coletiva: Atenção Básica", desenvolvido pela Escola de Saúde Pública-RS

E-mail: christianek@ig.com.br

$\star \star \star$ Possui graduação em Serviço Social pela Universidade de Caxias do Sul e mestrado em Serviço Social pela Pontifícia Universidade Católica do Rio Grande do Sul. Especialista em Saúde Coletiva pela Escola de Saúde Pública de Porto Alegre.

$\star \star \star \star$ Psicóloga. Mestrado em Psicologia pela Pontifícia Universidade Católica do Rio Grande do Sul. Especialização em Saúde Pública pela Escola de Saúde Pública RS/Escola Nacional de Saúde Pública Sergio Arouca.

$\star \star \star \star \star$ Psicóloga. Mestrado em Educação pela Universidade Federal do Rio Grande do Sul e doutorado em Psicologia Clínica pela Pontifícia Universidade Católica de São Paulo. Docente do Programa de Pós-Graduação de Psicologia Social e Institucional e do Programa de Pós-Graduação de Saúde Coletiva, ambos da Universidade Federal do Rio Grande do Sul. Endereço: Rua Ramiro Barcelos, 2600, sala 212, Santana - Porto Alegre, RS, Brasil. CEP: 90035-003.

E-mail: simone.paulon@ufrgs.br 


\title{
Mental health GROUPS IN PRIMARY HeALTH CARE
}

\begin{abstract}
This is a qualitative intervention-research carried out in two teams of Primary Health Care which aimed to analyze the practices of care developed by mental health groups, as well as their correlation with the process of deinstitutionalization of madness embedded in the Brazilian psychiatric reform. The research used the following as investigation methods: interventions in the mental health groups, semi-structured interviews, workshops with professionals from the mental health groups and daily field reports. The results led to the understanding of the mental health groups as deinstitutionalizing devices, when they provide psychosocial care, use the health network and the territorial resources, foster the expansion of social ties and allow participants to be recognized as protagonists of their own lives. The outcomes also indicated the coexistence of the forms of sheltering and psychosocial care in professionals' practices. Continuing education and multidisciplinary exchanges were pointed out as strategies to strengthen psychosocial care.
\end{abstract}

Keywords: Primary Health Care; Mental Health; Groups; Deinstitutionalization; Intervention-research.

\section{INTRODUÇÃo}

Este artigo resulta de pesquisa realizada em grupos de saúde mental e equipes de Atenção Primária à Saúde (APS), vinculadas ao Centro de Saúde-Escola Murialdo (CSEM), ${ }^{1}$ Escola de Saúde Pública do Rio Grande do Sul (ESP/RS), onde são oferecidos os programas de Residência em Medicina de Família e Comunidade e de residência multiprofissional, a Residência Integrada em Saúde com ênfase em APS. De acordo com Busnello (1976), o CSEM é pioneiro no desenvolvimento de ações de saúde mental na APS, tendo iniciado na década de 1960, com o primeiro programa de Psiquiatria Comunitária do Brasil, e se consolidado a partir de 1974, com a elaboração de um serviço de saúde mental comunitária. Os grupos de saúde mental se constituem em uma de suas ações, contando com público alvo, predominantemente, usuários com transtornos mentais severos e/ou persistentes, em uso de psicofármacos.

Observou-se e coordenou-se dois destes grupos durante realização da residência multiprofissional. Esta pesquisa foi motivada pela reflexão de que somente a realização de grupos na comunidade não garante o trabalho na perspectiva da desinstitucionalização, tornando-se necessário avaliar os objetivos, pressupostos e práticas neles desenvolvidas. 
Devido à carência de estudos específicos na literatura sobre grupos de saúde mental na APS, na lógica da atenção psicossocial, este estudo pretende inspirar novas investigações, contribuindo com a produção de conhecimentos e o fortalecimento da área. Busca, ainda, oferecer subsídios para que os profissionais da saúde desenvolvam e reflitam sobre a potência desinstitucionalizante deste instrumento de trabalho.

\section{Saúde Mental na Atenção Primária À Saúde: um potente encontro}

$\mathrm{O}$ atual modelo de atenção ${ }^{2}$ à saúde mental, norteado pelos princípios da reforma psiquiátrica brasileira, tem como principal diretriz a ampliação e qualificação do cuidado às pessoas com transtornos mentais nos serviços comunitários e a reestruturação da assistência psiquiátrica hospitalar. Configura-se como uma mudança na concepção e na forma de cuidado, buscando perceber o sujeito em sua existência-sofrimento e superando o foco na perspectiva da doença (BRASIL, 2005; COSTA-ROSA, 2000).

A principal diretriz da Política Nacional de Saúde Mental consiste na redução gradual e planejada de leitos em hospitais psiquiátricos, com a desinstitucionalização de pessoas com longo histórico de internações. Concomitantemente, prioriza a implantação de serviços e ações de saúde mental de base comunitária, capazes de atender com resolubilidade os usuários que necessitem de atenção (BRASIL, 2005). A desinstitucionalização pressupõe transformações culturais e subjetivas na sociedade e nas práticas de cuidado desenvolvidas pelos profissionais de saúde. Implica trabalhar com as estratégias de podersaber que constituem os processos de subjetivação determinantes de uma dada forma de lidar com a loucura (PAULON, 2003).

A reforma psiquiátrica, que coloca em funcionamento a desinstitucionalização, propõe "forjar um novo conceito no lugar de doença, um novo objeto que reavalie o fenômeno da loucura, sem escamotear sua complexidade, ao mesmo tempo que impeça ser ela, a loucura, capturada na doença" (TORRE; AMARANTE, 2001, p. 80). Propõe que o objeto, ao invés de ser "a doença", seja a existência-sofrimento dos sujeitos, relacionada ao corpo social e busca colocar entre parênteses a doença, sem negar que existe algo que produz o sofrimento.

O modo de atenção psicossocial indica a necessidade de serem construídas oportunidades para pessoas com problemas de saúde mental de exercerem sua cidadania e de atingirem seu potencial de autonomia no território em que vivem. A atenção psicossocial convoca a clínica a se ampliar e a produzir outras formas de cuidado, produzindo a ampliação do objeto de trabalho e a busca de resultados eficientes, incluindo novos instrumentos (BRASIL, 2009). A clínica ampliada é uma prática que parte do "núcleo biomédico para os aspectos subjetivos e sociais de cada sujeito, respeitando a característica singular de cada caso [...] sem abrir mão de critérios técnicos previamente definidos (diretrizes clínicas, programas, etc.)" (CAMPOS; GUERREIRO, 2010, p. 138). 
No Brasil, na perspectiva da atenção psicossocial, a rede de saúde mental é composta por diversas ações e serviços, tais como, centros de atenção psicossocial (CAPS), ambulatórios, residenciais terapêuticos, leitos de atenção integral em saúde mental em hospital geral, cooperativas de trabalho e geração de renda, ações de saúde mental na APS, entre outros (BRASIL, 2009).

A Organização Mundial de Saúde (OMS), em seu relatório de 2001 sobre a Saúde do Mundo, enfatiza que a Saúde Mental na APS torna o atendimento mais efetivo. Além de mobilizar a comunidade e ser economicamente favorável, a APS busca a integralidade, atua no território e com o contexto familiar, procura a continuidade do cuidado e busca articular-se com a rede de atenção (ORGANIZAÇÃO MUNDIAL DE SAÚDE, 2001). A OMS e a Associação Mundial de Médicos de Família (WORLD HEALTH ORGANIZATION AND WORLD ORGANIZATION OF FAMILY DOCTORS, 2008) referem que o manejo e o tratamento de transtornos mentais no contexto da APS é um passo fundamental para possibilitar ao maior número de pessoas o acesso mais facilitado e rápido aos serviços. Isso não só proporciona uma atenção de melhor qualidade como também reduz o desperdício resultante de exames supérfluos e de tratamentos impróprios ou não específicos. Entre as principais razões para a integração de saúde mental na APS destacam-se: relevante magnitude e prevalência dos transtornos mentais e baixo número de pessoas recebendo tratamento, aumento do acesso aos cuidados em saúde mental, ações e serviços que propiciam o respeito aos direitos humanos, redução de custos indiretos com a procura de tratamento em locais distantes e bons resultados na saúde de sujeitos com transtornos mentais.

Segundo dados internacionais de prevalência adotados pelo Ministério da Saúde (BRASIL, 2009), 3\% da população apresenta transtornos mentais severos e persistentes, necessitando de cuidados contínuos. De 9 a $12 \%$ da população possui transtornos mentais leves, precisando de cuidados eventuais. Grande parte destas pessoas estão sendo atendidas na APS, demonstrando que, cotidianamente, essas equipes se deparam com problemas de saúde mental. Ainda, a OMS e o Ministério da Saúde (ORGANIZAÇÃO MUNDIAL DE SAÚDE, 2001) estimam que quase $80 \%$ das pessoas encaminhadas para os profissionais de saúde mental não trazem, a priori, uma demanda específica que justifique a necessidade de atenção especializada.

Desta forma, as equipes da APS constituem-se como um recurso estratégico para acolher e cuidar da pessoa portadora de algum transtorno mental, respeitando-a como um sujeito de direitos e proporcionando atenção mais próxima da sua rede familiar, social e cultural (BRASIL, 2005). Contudo, nem todos profissionais sentem-se confiantes para dar conta dessa tarefa. Os modelos atuais de desenvolvimento e formação profissionais para o SUS têm deixado lacunas referentes ao aprendizado do cuidado, gerando deficiências de ordens técnicas, políticas e gerenciais nos serviços de saúde. A falta de capacitação prejudica o desenvolvimento de ações integrais. Além disso, atender às pessoas com transtornos mentais é, de fato, uma tarefa complexa (BRASIL, 2003). Assim, torna- 
se necessário fortalecer as equipes de APS para o desenvolvimento de ações de saúde mental de acordo com os princípios da reforma psiquiátrica, promovendo outras formas de ver, se relacionar e tratar a loucura.

Neste sentido, esta pesquisa objetiva analisar as práticas de cuidado desenvolvidas nos grupos de saúde mental ocorridos na APS e a sua correspondência com os processos de desinstitucionalização da loucura, inscritos na reforma psiquiátrica brasileira. Tem como objetivos específicos: a) associar as práticas de cuidado, que perpassam os grupos de saúde mental e as duas equipes de APS, aos modos de atenção asilar e psicossocial; e b) identificar os movimentos de institucionalização e de desinstitucionalização observáveis no processo dos grupos de saúde mental em questão.

\section{Percurso metodológico da Pesquisa-InTervenção}

Trata-se de uma pesquisa qualitativa, estruturada na modalidade da Pesquisa-Intervenção que busca investigar a vida das coletividades na sua diversidade e adota uma intervenção de caráter socioanalítico (ROCHA; AGUIAR, 2003) em que pesquisar torna-se imediatamente interferir e intervir (PAULON et. al., 2003). A Pesquisa-Intervenção surge da abordagem aos fenômenos sociais, dando visibilidade ao jogo de interesses e de poder encontrados no campo de pesquisa. Tem como suporte teórico e metodológico a Análise Institucional Socioanalítica e a Esquizoanálise, correntes do movimento institucionalista, no seguimento dos trabalhos da Psicoterapia Institucional e da Pedagogia Institucional. Teve entre seus principais articuladores os sociólogos Lapassade e Lourau, bem como as ideias dos filósofos Nietzsche, Foucault e Deleuze (PAULON et. al., 2003). O objetivo da intervenção institucional consiste na autoanálise e na autogestão.

Os participantes desta pesquisa são dois grupos de saúde mental, compostos por quatorze e dezesseis usuários portadores de transtorno mental e duas equipes de APS, compostas por dezesseis e dezessete profissionais, respectivamente. $\mathrm{Na}$ discussão dos resultados os usuários serão identificados pela sigla U e os profissionais pela letra P. A pesquisa utilizou diferentes métodos de investigação: intervenção nos grupos de saúde mental, entrevistas semiestruturadas e oficinas com os profissionais das equipes e registro em diário de campo. Os grupos de saúde mental foram coordenados e analisados pelas pesquisadoras, na freqüência de uma vez por semana, com duração de uma hora, em espaço comunitário. A pesquisa ocorreu durante doze meses, contemplando trinta e seis encontros do grupo um e quarenta e seis do grupo dois.

Foram realizadas quatro entrevistas semiestruturadas com profissionais que acompanharam o início dos grupos de saúde mental, com o objetivo de coletar dados sobre a história destes grupos. Outras sete entrevistas ocorreram com profissionais de diferentes especialidades que atuavam nas equipes de APS, como médicos de família e comunidade, enfermeiros, odontólogos, nutricionistas, psicólogos, psiquiatras e assistentes sociais, com o objetivo de conhecer suas concepções de loucura e de cuidado em saúde mental. Realizou-se ainda, duas oficinas, uma em cada equipe, objetivando a reflexão sobre as práticas de cuidado em saúde mental. 
A pesquisa utilizou a análise de implicação e os analisadores como seus instrumentos de orientação na análise dos achados. O conceito de implicação se refere à análise do sistema de lugares ocupados, ou que se busca ocupar, ou do que é designado (ROCHA; AGUIAR, 2003). A intervenção evidencia que pesquisador e pesquisado fazem parte do mesmo processo. Dessa forma, o procedimento de aproximação com o campo inclui sempre a permanente análise do impacto que as cenas vividas e observadas têm sobre a história do pesquisador e sobre o sistema de poder que legitima o instituído, incluindo aí o próprio lugar de saber e o estatuto de poder do pesquisador (PAULON, 2005).

A intervenção de que trata esta modalidade de pesquisa trabalha no sentido de produzir ou identificar possíveis analisadores, entendidos como eventos ou acontecimentos que, por condensarem questões políticas, afetivas, conflitivas do coletivo, trazem à tona dimensões de seu cotidiano dificilmente explorado. Alguns analisadores são naturais e emergem espontaneamente e outros podem ser criados pelos pesquisadores (analisadores artificiais), a fim de disparar mudanças nas lógicas instituídas e auxiliar na autoanálise e autogestão dos coletivos. Os analisadores tornam-se dispositivo quando conseguem produzir rupturas no instituído e brechas na homogeneidade dominante, vislumbrando saídas (BARROS, 1997).

A forma de tratamento dos achados alinha-se ao princípio da PesquisaIntervenção que preconiza a interlocução continuada pesquisador - público alvo - campo de pesquisa. As categorias de análise elencadas e apresentadas a seguir foram organizadas a partir de um conjunto de analisadores que emergiram no decorrer da pesquisa e da permanente análise de implicação das pesquisadoras. Tais categorias foram problematizadas durante as intervenções, remetendo os sujeitos da pesquisa a refletirem sobre suas relações com as concepções de saúde mental, com as práticas de cuidado e com a reforma psiquiátrica. O que, por sua vez, possibilitou o reconhecimento de processos de institucionalização das práticas, dos usuários e dos trabalhadores, bem como permitiu a emergência ou construção de dispositivos que provocaram mudanças rumo à desinstitucionalização.

Esta pesquisa foi aprovada pelo comitê de ética em pesquisa da Escola de Saúde Pública do Rio Grande do Sul e o termo de consentimento livre e esclarecido foi assinado pelos participantes, garantindo o sigilo de dados identificatórios. No caso daqueles usuários dos grupos de saúde mental que não respondiam legalmente por si, foi solicitada a autorização do curador responsável.

\section{RESUltados: ANÁLISE E DISCUSSÕES}

\section{Fragmentos da história dos Grupos de Saúde Mental pesquisados}

A partir das entrevistas com os profissionais, identificou-se que, dentre as ações de desenvolvidas na consolidação da saúde mental no CSEM em 1974, destaca-se o Programa de Atendimento às Psicoses, criado com o intuito de evitar os prejuízos das internações hospitalares prolongadas e de diminuir o ônus 
econômico do Estado, que investia seus recursos maciçamente em um hospital psiquiátrico. Este hospital desenvolvia ações objetivando o acompanhamento dos pacientes egressos das internações psiquiátricas pelas equipes de APS.

Neste contexto, uma das estratégias do CSEM foi a criação do "Grupo dos Nervosos" para a observação direta dos pacientes e para renovação de receitas. Assim, surgiu um dos grupos de que trata esta pesquisa. Seu público alvo consistia, prioritariamente, de pessoas com transtorno mental, egressas das internações psiquiátricas e de pessoas que necessitavam de medicação psicotrópica. No início do grupo havia cartazes expostos pela unidade básica de saúde referindo: "Se você é nervoso e anda brigando muito na sua casa, venha nos procurar" (P1). Este "grupo foi criado pensando-se em oferecer um atendimento integral a estes pacientes, acreditando que o grupo rende mais do que somente as consultas individualizadas. A ideia foi a de atender melhor, com todas as especialidades envolvidas" (P7).

O outro grupo estudado iniciou na década de 1990 por demanda da residência em Psiquiatria Comunitária, desenvolvida em um Hospital Geral que tinha o CSEM como um campo de estágio, mantendo um objetivo e público alvo semelhantes, além de estimular o convívio social. Ou seja, o grupo possuía também a função de ser uma "atividade social" para os seus participantes, já que muitos apresentavam dificuldades na circulação social e na formação de outros laços afetivos, demonstrando dificuldades no exercício de sua autonomia. Esse caráter de atividade social referia-se à existência de festas e comemorações durante os encontros grupais.

Em meados de 2000, ambos os grupos passaram por transformações. Os seus objetivos foram revistos, passando a ter caráter terapêutico, com o foco voltado para a promoção de saúde. Através do dispositivo grupal, passou-se a estimular o autocuidado, a autonomia e a (re) descoberta das potencialidades dos portadores de transtornos mentais, buscando propiciar novos agenciamentos sociais através de recursos do território, além de problematizar a estigmatização da loucura. A pesquisa deu-se em um momento em que tais mudanças estavam se consolidando.

\section{Categorias de Análise}

\section{Território-cidade}

Esta categoria aponta o modo como os participantes dos grupos de saúde mental se relacionavam com o território, bem como seu potencial de ampliação da circulação social. Os resultados indicam que os referidos grupos podem funcionar como um espaço de transição e elo entre o sujeito e o território, ampliando a experiência subjetiva dos participantes e expandindo os seus horizontes existenciais, como se observa na fala de um usuário: "não sentia vontade de sair de casa, tinha medo de andar sem a companhia de familiares. Depois que comecei a frequentar o grupo, estou mais segura, já faço compras sozinha!” (U1). 
Entretanto, acredita-se que o grupo de saúde mental é um dispositivo desinstitucionalizante e de ampliação da autonomia, quando potencializa a criação de novos laços sociais, não sendo o único espaço de socialização dos sujeitos. Quando o objetivo do grupo consiste somente em promover a convivência entre os seus participantes, sem mobilizar questionamentos e transformações na forma de relação com os espaços sociais, a situação de exclusão permanece.

Como a maioria dos participantes dos grupos pesquisados já se encontrava em uma situação de isolamento social e de exclusão devido ao modo como a sociedade lida com a loucura e com a doença mental, o grupo era facilmente tomado como o único espaço de circulação para além da casa. Os grupos tinham em sua história, períodos em que o objetivo era promover somente o convívio entre os participantes: "Teve uma época que o grupo era um 'encontro social', em que se investia em passeios, piqueniques. Outra época era 'um grupo de convivência' com rifas e festas" (P1).

Um dos desafios da reforma psiquiátrica é a utilização do território enquanto promotor de saúde. Sendo assim, deve-se aproveitar o espaço da comunidade como facilitador na ampliação da circulação e do estabelecimento de novas relações sociais, pois por ser um espaço protegido, em que já se viveu parte da vida e no qual há vizinhos com quem se tem algum vínculo, isso pode fortalecer os usuários para se lançarem no espaço público de um modo mais seguro. Com o objetivo de estimular os participantes dos grupos a retomar ou iniciar atividades sociais, que envolvessem a circulação na cidade e que fossem consonantes com suas histórias de vida, foram realizadas algumas ações. Um dos grupos participou de atividade comemorativa do estado, enquanto o outro realizou um passeio turístico de ônibus pela cidade de Porto Alegre. Apareceram aspectos que até então não haviam tido visibilidade: o paciente estigmatizado como louco era o que sabia onde era a parada de ônibus, era o que guiava o grupo; na discussão sobre o passeio, as histórias dos participantes que nunca antes eram contadas sem que a doença fosse o principal foco, puderam ser resgatadas com um colorido de imagens e cenas: "Ah, doutora, a senhora provavelmente não andou de bonde como nós, era muito legal, eu ia com meu pai pro centro quando era criança e andava, eu adorava" (U2); "Lá na minha cidade, onde vivi minha infância, eu não precisava de ônibus, tudo era perto. Nossa! Eu conhecia tudo e gostava de visitar as pessoas" (U1).

A experiência de percorrer a cidade permitiu que novas paisagens fossem vistas e que aparecessem outras posições subjetivas: "Eu quero levar meu filho para passear com este ônibus, como meu pai fazia comigo nos bondes" (U2); "Passear junto com as doutoras fez a gente se aproximar e ver que os doutores são gente como nós" (U3).

Dessa forma, os dados da pesquisa indicaram que ao se ampliar os horizontes de circulação dos sujeitos, o território-cidade passa a promover saúde e a reabilitar, pois potencializa o estabelecimento de novos vínculos e novas significações na rede de contratualidade do sujeito. Ressalta-se que, de acordo com 
Tykanori (1996), reabilitar refere-se à construção ou reconstrução do poder contratual do paciente, criando possibilidades para que ele possa participar do processo de trocas sociais, com vistas a ampliar sua autonomia.

\section{$\underline{\text { Singularidade }}$}

Esta categoria refere-se ao grupo de saúde mental auxiliar na responsabilização dos usuários pelo tratamento, pelos seus sintomas e pela sua vida, o que envolve outra relação com a psiquiatria, com os medicamentos e com a saúde. A singularidade aqui se expressa como uma forma dos usuários dos grupos se voltarem a si próprios, percebendo-se como sujeitos, e não apenas como portadores de um diagnóstico e dependentes de psicofármacos. Todavia, o movimento de autorreconhecimento para além da doença e dos efeitos dos medicamentos foi um dos pontos mais instigantes durante a pesquisa, visto a autopercepção dos usuários.

Muitos participantes dos grupos enfatizavam o tratamento medicamentoso: "O nosso lema é a medicação" (U14). A maioria associava suas sensações e afetos à eficácia ou ao fracasso do medicamento, facilitando a desresponsabilização com seus próprios sintomas, os quais eram percebidos como tendo vida própria, como se fossem estrangeiros: "Não sei, eu tô bem e de repente eu fico mal, fico triste, acho que é quando o remédio pára de fazer efeito" (U2).

Identificou-se também que a forma de agir e de pensar da maioria dos usuários, nos diversos espaços sociais tais como família e comunidade, aliava-se à prerrogativa de que o medicamento ou a falta dele justificava o comportamento e a manifestação de suas emoções: "Doutora, não sei, eu ando triste, chorando muito, sei que é porque eu sou depressiva, mas não quero sentir isso, será que o doutor aumenta a minha fluoxetina?" (U4). Ressalta-se que a usuária havia perdido um familiar há uma semana e não conseguia associar sua tristeza com a perda, já que tudo para ela era devido à depressão.

Em alguns encontros do grupo surgiu a discussão sobre a experiência da loucura. Um dos participantes comenta que alguns adolescentes o chamam de louco e atiram pedras na sua casa, o que lhe causa muita irritação. Ele fala direcionando-se aos demais pacientes: "Eu sou louco mesmo, saio de facão atrás deles" (U5). As falas que emergiram após este relato demonstraram que para alguns participantes a irritação é tão intensa, que remete ao descontrole emocional e os faz acreditar que essa emoção só aconteça com quem tem "problema nos nervos". O questionamento da associação irritabilidade-raiva/doença-loucura pelas pesquisadoras provoca a reflexão sobre a singularidade de cada experiência vivida e de cada sentimento. Em alguns casos, percebeu-se que o peso da instituição loucura impossibilitava o desprendimento do lugar de doentes, devido à intensidade da experiência de estar no limite entre a sanidade/loucura, sendo esta tensão minimizada pelo medicamento e pelo especialista 'psi' (psiquiatra e psicólogo): "Doutoras será que o psiquiatra vem hoje? Eu acho que ele esqueceu da gente". Alguns minutos depois o psiquiatra chega e é recebido sob palmas: "Que bom que o doutor veio. A gente não pode ficar sem médico no grupo" (U6). 
Também, se percebeu uma identificação dos usuários com sua doença, o que pode ser ilustrado pela fala: "Ah, eu não posso me incomodar, porque eu sou depressiva, então quando eu vejo que vai acontecer alguma coisa que pode mexer comigo, eu me tranco no quarto e tomo um comprimidinho a mais pra ficar calma" (U4). Tal identificação muitas vezes os eximia de algumas responsabilidades, bem como da busca de outras alternativas de vida, o que os recolocaria na dinâmica social e familiar como sujeitos ativos.

Para produzir rupturas nesta lógica, as intervenções buscavam incidir sobre a desmedicalização da demanda, subjetivando as queixas dos usuários, questionando a lógica de que o psiquiatra é o único que sabe e de que o medicamento é o único agente de mudanças. De acordo com Oliveira (2000), a preocupação dos profissionais de saúde deve consistir em oferecer uma escuta que leve em conta o sujeito por trás de seus sintomas, auxiliando o portador de transtorno mental a resgatar sua posição de sujeito, agente e protagonista.

Os resultados indicam que o trabalho grupal com foco no resgate da singularidade possibilita o reposicionamento subjetivo das pessoas com transtornos mentais, as quais passam a se responsabilizar mais por seu sofrimento e a se reconhecer como agentes de mudanças: "Eu estou gostando do grupo neste ano, acho que está mais terapêutico. Antes eu achava que tinha que ter um médico, aí vocês começaram a falar que a gente tinha que cuidar da gente, no começo deu medo, assustou. Porque a doutora [psiquiatra] era um amor, no final do grupo ela falava com a gente, a gente dizia o que tava sentindo e ela aumentava o remédio, era como se a gente fosse embalado no colo, como um bebê. Mas agora, sem o médico, a gente tem que andar com nossos próprios pés, que é bom, eu me sinto melhor" (U7).

\section{$\underline{\text { Cuidado }}$}

Essa categoria indica o modo como as equipes e os grupos de saúde mental promovem as práticas de cuidado. Para fins de análise, utiliza-se como referência os dois modos de atenção predominantes na área da saúde mental: o asilar e o psicossocial. De acordo com Costa Rosa (2000), o modo asilar corresponde às práticas de cuidado centradas nos aspectos biológicos, no diagnóstico e no medicamento.

O modo psicossocial, situado em contraposição ao asilar, considera os fatores políticos e biopsicosocioculturais como determinantes do transtorno mental, sendo decisiva a participação do sujeito no seu tratamento. Os seus meios básicos de tratamento incluem diversas formas como psicoterapias, laborterapias, socioterapias e um amplo conjunto de dispositivos de reintegração sociocultural, além do medicamento. Objetiva uma mudança na forma de relação dos usuários consigo mesmos, com o medicamento, com a família, com o tratamento e com a própria psiquiatria, dando ênfase à reinserção social.

No processo da Reforma Psiquiátrica brasileira existem várias experiências de cuidado às pessoas portadoras de transtornos mentais que desconstroem a ética hegemônica e vivenciam outros valores em relação aos direitos dos usuários, assim, como outras formas de clínica que vêm sendo nomeadas de diver- 
sas formas: "clínica ampliada, clínica da referência, clínica do sujeito, clínica na crise, clínica sem manicômios, clínica transdisciplinar, clínica da atenção psicossocial" (GRIGOLO, 2010, p. 43).

Os resultados deste estudo indicaram a coexistência dos dois modos de atenção no cuidado em saúde mental promovido pelas equipes. A concepção que os profissionais têm de saúde e transtorno mental, sua etiologia e, consequentemente, o tratamento proposto aparecem predominantemente vinculados ao modo asilar: "O que nós vemos muito na unidade é a medicalização. Ah tá deprimido, vamos dar um antidepressivo, então, é só na base do medicamento, às vezes a pessoa, ela quer só sentar e conversar." (P2).

Verificou-se, também, um entendimento de que cuidar em saúde mental seria responsabilidade dos especialistas $p s i$, o que pareceu se relacionar à presença histórica de diversos especialistas nas equipes do CSEM, reforçando a fragmentação das práticas. As equipes que não contavam com o psiquiatra tinham dificuldade de lidar com a demanda: "Nós não temos profissionais especializados nisso. Os nossos médicos são generalistas, os especialistas pouco param na unidade, o que a gente vai fazer com essa população? (P2).

Da mesma forma, a presença de residentes de psiquiatria em um dos grupos gerou uma demanda específica e a solução encontrada pela equipe foi aumentar a oferta desta especialidade, ao invés de priorizar a capacitação de outros profissionais: "A gente tem uma demanda gigante em saúde mental. Este é um dos motivos que fez a UBS [Unidade Básica de Saúde] abrir mais vagas, nós temos quatro turnos de psiquiatria aqui” (P3).

A intervenção nos grupos problematizou o modo asilar, objetivando fortalecer a atenção psicossocial. Por exemplo, a partir da diminuição de participantes nos encontros de um dos grupos, foi proposto que se fizesse uma avaliação. Foram destacados como problemas: estigma e preconceito; família não compreendendo o transtorno mental; pessoas que comparecem ao grupo somente quando estão mal; renovação de receita não pode ser feita no grupo; não ter médico psiquiatra acompanhando o grupo. Buscavam no grupo: aconchego, tranquilidade, compreensão, espaço para comunicação e diálogo, escuta dos colegas, melhora da saúde, sentir-se bem, não ser cobrado, ajudar os amigos do grupo, socialização. Sugestões: organizar um grupo de familiares; realizar caminhadas, passeios e atividades; assistir filmes com mensagens positivas; conhecer outros grupos de saúde mental; ter um psiquiatra, renovar receitas e agendar consultas no grupo.

Percebe-se que a partir da referida avaliação apareceram necessidades de outras práticas de cuidado. Ao mesmo tempo em que os usuários priorizaram o enfoque biológico e medicamentoso, através da solicitação por psiquiatra e por renovação de receita (modo asilar), demandaram espaços de escuta, trocas afetivas e inserção da família no tratamento (modo psicossocial).

Acredita-se que para as práticas promoverem a desinstitucionalização, deve-se investir em um cuidado vinculado ao modo de atenção psicossocial. Alguns dispositivos podem ser utilizados para este fim, como a educação permanente, 
que promove a qualificação a partir da reflexão sobre situações práticas do cotidiano. Outra ação potente é a discussão com os trabalhadores sobre o cuidado oferecido, proporcionando um entendimento de cada usuário como alguém singular, com necessidades próprias, desmistificando a concepção de loucura e ampliando a concepção de cuidado. A construção de projetos terapêuticos singulares pode-se dar a partir desses espaços de reflexão. Outro dispositivo é a consulta conjunta com profissionais mais vinculados à saúde mental, tais como Psicologia, Psiquiatria e Serviço Social, conforme sugere um dos participantes: "Eu acho que a interconsulta é que vai delinear: que o paciente tem que ser acompanhado pela pessoa que ele tem vínculo, [...] e tentar discutir com as psicólogas" (P4).

\section{$\underline{\text { Rede }}$}

Esta categoria compreende dois aspectos: "rede equipe" e "rede serviços". A "rede equipe" é formada pela troca de saberes e conhecimentos entre a equipe de profissionais que atuam na APS, para compor a atenção em saúde mental. Já a "rede serviços" consiste no conjunto de serviços, equipamentos especializados em saúde mental e espaços comunitários que podem ser acessados pelos usuários para a ampliação de sua saúde.

Em relação à "rede equipe", buscou-se avaliar como os profissionais concebiam o tratamento em saúde mental e se discutiam coletivamente os casos, construíam projetos terapêuticos singulares e trocavam entre si, buscando uma prática ampliada em saúde mental, com vistas à atenção psicossocial. Ressalta-se que, de acordo com a Política Nacional de Humanização (BRASIL, 2008), o projeto terapêutico singular consiste em um conjunto de propostas de condutas terapêuticas articuladas, para um sujeito individual ou coletivo. Resulta da discussão em equipe em que todas as opiniões são importantes para entender o sujeito e suas necessidades em saúde e, consequentemente, para definição de propostas de ações.

A partir dos dados obtidos por esta pesquisa, verificou-se que são poucos os espaços disponíveis para a troca entre os profissionais para a condução dos casos. Pouco se investia nesta interação e tampouco apareciam nos planos de ação ou planejamentos anuais dos serviços enquanto uma ação prioritária. Além disso, os profissionais apontaram para a necessidade de qualificação e capacitação em saúde mental, enquanto possibilidade de construção de um cuidado baseado no modo psicossocial, realizado em equipe: "Acho que tem algumas coisas que eu dou conta, eu acho que eu consigo [...] quando busco supervisão e interconsulta. Falta capacitação [...], falta um entendimento nosso de que a gente pode e deve trabalhar algumas questões. A questão da saúde mental é uma questão muito pesada pra ficar na mão de duas, três pessoas só, tinha que ser uma coisa mais da equipe" (P4).

No que se refere à "rede serviços", buscou-se identificar se os profissionais conheciam os serviços de saúde mental considerados referência para a Unidade, bem como os recursos comunitários presentes no território e se os mesmos faziam parte do projeto terapêutico singular. A maioria dos profissionais desconhecia os serviços especializados, exceto alguns hospitais psiquiátricos e não percebia os recursos da comunidade como importantes para a construção do projeto terapêu- 
tico de cada usuário. Sendo assim, as intervenções estavam focadas nos atendimentos individuais e nos encaminhamentos para os especialistas $p s i$, atuando sem considerar a rede de saúde e comunitária como potencializadora de saúde. Além disso, percebeu-se que o desconhecimento da rede gerava impotência: "Não conhecemos os espaços para onde podemos encaminhar o paciente. Não sei que tipo de paciente pode participar de oficinas" (P4). "Não sei como se encaminha para o CAIS Mental [serviço equivalente a um Centro de Atenção Psicossocial, no território em questão]" (P5).

Por outro lado, quando as equipes identificavam a "rede serviços" como recurso terapêutico, potencializava-se a relação entre usuário e o serviço de saúde: "Quanto mais as pessoas encontrarem recursos internos, quanto mais elas acessarem a rede, buscarem outras coisas, menos medicação, menos internação, menos PA [Pronto Atendimento]. Nosso papel é o de reforçar as potencialidades" (P1).

O trabalho em saúde mental que leva em consideração as trocas e construções em equipe, que conta com uma rede de saúde de apoio, bem como investe nos recursos comunitários e sociais, tende a culminar na oferta de um cuidado ampliado em saúde mental. Isso permite a resignificação do sujeito para além de um lugar de doente e de louco, possibilitando a construção de novos contratos sociais e que apontem para o resgate da singularidade: "Procurando integrar o paciente no meio aonde ele vive, então, a gente tem que ter disponibilidade pra ele, que ele tenha acesso" (P6).

"Rede equipe" e "rede serviços" podem ser entendidas como ferramentas que reformulam as noções de cuidado em saúde mental. O projeto terapêutico singular passa a ter como objetivo o auxílio do paciente a viver e, não mais, silenciar seus sintomas, permitindo um melhor gerenciamento sobre sua vida, ampliando a contratualidade social e a reabilitação. Também se transforma a noção de tratamento, vinculada agora à escuta, à diversidade, ao vínculo, à interdisciplinaridade, à intersetorialidade e ao território.

A partir das entrevistas e das oficinas com as equipes de saúde, os profissionais passaram a demandar mais esclarecimentos sobre a "rede serviços", como por exemplo, solicitaram a lista dos equipamentos de saúde mental de referência. Porém, identificou-se a necessidade de maior aprofundamento da discussão sobre rede para além do simples encaminhamento de referência e contrarreferência, que considere a singularidade de cada caso e a construção de projetos terapêuticos singulares. Ainda, destacou-se a importância de fortalecer o debate sobre a coordenação da atenção em saúde mental a partir da APS. No que tange à rede equipe, percebeu-se um considerável avanço, o que pode ser evidenciado por maiores trocas entre os profissionais sobre a condução dos casos de saúde mental e pela solicitação de mais consultas conjuntas aos psicólogos e psiquiatras. 


\section{CONSIDERAÇÕES FINAIS}

Esta pesquisa identificou que os grupos de saúde mental desenvolvidos na APS se constituem em um dispositivo da reforma psiquiátrica quando promovem aos seus participantes rupturas nas suas formas de cuidado com a vida, possibilitando que se reconheçam enquanto corresponsáveis pelo seu tratamento e pelo seu modo de ser. Desta forma, o grupo de saúde mental, na perspectiva da atenção psicossocial, institui mudanças na relação dos usuários consigo mesmos, com o tratamento e com a lógica dos especialismos na saúde mental. No decorrer da pesquisa, percebeu-se em vários momentos o reposicionamento de usuários, que passaram a se colocar como sujeitos e agentes de sua saúde, dialogando mais com os técnicos e questionando os procedimentos e prescrições que lhes eram destinados. Porém, em outros episódios, oscilavam como que capturados pela lógica biomédica, colocando a origem dos seus problemas no orgânico e a solução no medicamento.

As intervenções buscaram fortalecer o modo de atenção psicossocial, apostando no resgate da singularidade de cada usuário, investindo no comprometimento com seus sintomas e tratamento e incentivando seu protagonismo. Tais movimentos incitaram a ruptura com a lógica da identificação dos sujeitos com a doença e com a concepção de cura restrita à solução medicamentosa. Ainda, procurou-se auxiliar na construção de outros laços sociais, para além do grupo, apostando na força do território e da cidade como alternativas para a reabilitação psicossocial.

Os resultados assinalam que este trabalho conseguiu ir além das práticas oferecidas pelos espaços dos grupos, possibilitando às equipes de saúde a reflexão sobre alternativas para mudanças formas de cuidar. Buscou-se gerar um olhar ampliado dos profissionais para o portador de transtorno mental e o compartilhamento das responsabilidades entre especialidades. Apontaram ainda para a necessidade de criar e fortalecer espaços de educação permanente tais como capacitações e trocas entre os profissionais das equipes de APS para a discussão de casos clínicos, construção de projetos terapêuticos singulares e construção de propostas de cuidado em saúde mental ampliadas, para além da medicação e internação.

Ressalta-se que a Saúde da Família, estratégia priorizada pelo governo brasileiro para reorganizar a APS, aponta para um contexto mais favorável à atenção psicossocial do que a conjuntura em que essa pesquisa ocorreu. Segundo Nunes e Jucá (2007) a Saúde da Família conta com os agentes comunitários de saúde que, por serem residentes da comunidade e por trabalharem no território, funcionam como elo de ligação entre a população e a equipe de saúde e se destacam pelo contato com os casos de sofrimento mental, procurando lidar de modo contínuo com essas situações.

Ainda, os Núcleos de Apoio à Saúde da Família (NASF) potencializam a centralidade da atenção no território e na família, configurando um arranjo favorável para práticas humanizadas de cuidado em saúde mental. O NASF promove a criação de espaços para a produção de novos saberes e ampliação da clínica (BRASIL, 2009). Através do apoio matricial (CAMPOS, 2007) o NASF objetiva assegurar retaguarda especializada às equipes de Saúde da Família, favorecen- 
do a educação permanente, as consultas e atendimentos conjuntos, as discussões de casos clínicos, a construção de projetos terapêuticos singulares, dentre outras ações. Acredita-se que futuras pesquisas sobre ações de saúde mental desenvolvidas por essas novas estratégias governamentais aperfeiçoariam a área, potencializando a atenção psicossocial na APS.

\section{Notas}

${ }^{1}$ Instituição pertencente à Secretaria de Saúde do Estado na época da pesquisa, que abrangia sete Unidades Básicas de Saúde - UBS, localizadas no bairro Partenon do município do Porto Alegre, e que eram campo de formação para a Residência Integrada em Saúde - RIS - Atenção Básica, da Escola de Saúde Pública/RS. Atualmente, as UBS foram municipalizadas e a RIS está presente em Unidades de Saúde da Família e Núcleos de Apoio à Saúde da Família do Distrito Sanitário Partenon-Lomba do Pinheiro em POA, região metropolitana.

${ }^{2}$ Neste artigo utiliza-se o termo atenção para dialogar sobre os modelos de atenção em saúde mental e cuidado para abordar as práticas de cuidado desenvolvidas. Entende-se, concordando com Ballarin, Carvalho e Ferigato (2010), que o cuidado baseado no modo psicossocial é mais que construir um objeto e intervir sobre ele é, na verdade, ser capaz de acolher, dialogar, produzir novas subjetividades, exercitar a capacidade crítica, transformar criativamente os modos de ver, sentir, pensar já estabelecidos.

\section{REFERÊNCIAS}

BALLARIN, M. L. G.; CARVALHO, F. B.; FERIGATO, S . H. Os diferentes sentidos do cuidado: considerações sobre a atenção em saúde mental. O Mundo da Saúde. São Paulo, v. 34, n. 4, p. 444-450, out./dez. 2010.

BARROS, R. D. B. Dispositivos em ação: o grupo. In: LANCETTI (Org.). Saúdeloucura: Subjetividade, São Paulo: Hucitec, 1997. p. 183-191. v. 6.

BRASIL. Ministério da Saúde. Secretaria de Atenção à Saúde. Departamento de Atenção Básica. Diretrizes do NASF: Núcleo de Apoio à Saúde da Família. Brasília-DF: Ministério da Saúde, 2009.

BRASIL. Ministério da Saúde. Secretaria de Atenção à Saúde. Núcleo Técnico da Política Nacional de Humanização. Clínica ampliada, equipe de referência e projeto terapêutico singular. Brasília: Ministério da Saúde, 2008.

BRASIL. Ministério da Saúde. Secretaria de Atenção à Saúde. Departamento de Ações Programáticas e Estratégicas em Saúde. Coordenação Geral de Saúde Mental. Reforma psiquiátrica e política de saúde mental no Brasil. Brasília: OPAS, Ministério da Saúde, 2005. Documento apresentado à Conferência Regional de Reforma dos Serviços de Saúde Mental: 15 anos depois de Caracas.

BRASIL. Ministério da Saúde. Secretaria de Atenção à Saúde. Departamento de Ações Programáticas e Estratégicas e Departamento de Atenção Básica. Saúde mental e atenção básica: o vínculo e o diálogo necessários. Brasília: Ministério da Saúde, 2003. 
BUSNELlO, E. A Integração da Saúde Mental num Sistema de Saúde Comunitária. 1976. Tese (Livre-Docência em Psiquiatria) - Faculdade de Medicina do Rio Grande do Sul. Porto Alegre, 1976.

CAMPOS, G. W. S; GUERREIRO, A. V. P. Manual de práticas de atenção básica: saúde ampliada e compartilhada. São Paulo: Hucitec, 2010.

CAMPOS, G. W. S. Apoio Matricial e equipe de referência: uma metodologia para a gestão do trabalho interdisciplinar em saúde. Cadernos de Saúde Pública, Rio de Janeiro, v. 23, n. 2, p. 399-407, fev. 2007.

COSTA-ROSA, A. O Modo Psicossocial: um paradigma das práticas substitutivas ao modo asilar. In: AMARANTE, P. (Org.). Ensaios: subjetividade, saúde mental, sociedade. Rio de Janeiro: Fiocruz, 2000. p. 141-168.

GRIGOLO, T. M. O CAPS me deu voz, me deu escuta: um estudo das dimensões da clínica nos Centros de Atenção Psicossocial na perspectiva dos trabalhadores e dos usuários. 2010. Tese (Doutorado) - Universidade de Brasília, Brasília, 2010.

NUNES M., JUCÁ N.J., VALENTIN C.P.B. Ações de saúde mental no Programa Saúde da Família: confluências e dissonâncias das práticas com os princípios das reformas psiquiátrica e sanitária. Cadernos de Saúde Pública, Rio de Janeiro,v. 23, n. 10, p. 2375-2384, out. 2007.

ORGANIZAÇÃO MUNDIAL DE SAÚDE. Relatório sobre a saúde no mundo: Saúde Mental: nova concepção, nova esperança. Geneva: OMS, 2001.

OLIVEIRA, R. C. A recepção em grupo no ambulatório do IPUB/UFRJ. Cadernos do IPUB: a clínica da recepção nos dispositivos de saúde mental, Rio de Janeiro, v. 6, n. 17, p. $30-46$, abr. 2000.

PAULON, S. M. A análise de implicação como ferramenta na pesquisaintervenção. Psicologia \& Sociedade, Porto Alegre, v. 17, n. 3, p. 18-25, set./dez. 2005.

PAULON, S. M. et al. Desinstitucionalização da loucura, práticas de cuidado e a reforma psiquiátrica no RS. 2003. (Relatório de pesquisa). Universidade do Vale do Rio dos Sinos, São Leopoldo. 2003.

ROCHA, M. L. AGUIAR, K. F. Pesquisa-intervenção e a produção de novas análises. Psicologia: ciência e profissão, Brasília, v. 23, n. 4, p.64-73, out./dez. 2003.

TYKANORI, R. Contratualidade e reabilitação psicossocial. In: PITTA, A. (Org.). Reabilitação psicossocial no Brasil. São Paulo: Hucitec, 1996. 
TORRE, E. H. G.; AMARANTE, P. Protagonismo e subjetividade: a construção coletiva no campo da saúde mental. Ciência \& Saúde Coletiva, Rio de Janeiro, vol. 6, n. 1, p.73-85, jan./jun. 2001.

WORLD HEALTH ORGANIZATION AND WORLD ORGANIZATION OF FAMILY DOCTORS. Integrating mental health into primary care: a global perspective. Geneva: [s.n.], 2008.

Recebido em: 06 de setembro de 2010 Aceito em: 27 de junho de 2012 